ARTICLE

https://doi.org/10.1057/s41599-020-0391-x

\title{
Loaded objects: addressing gun violence through art in the gallery and beyond
}

Annie Dell'Aria ${ }^{1 \star}$

\begin{abstract}
Gun violence impacts our experience of public spaces, including how we represent and memorialize tragic events stemming from guns in public ways. Immediate memorials, complete with flowers and other ephemera, frequently appear at the sites of gun violence, at times to be followed by permanent memorials with contemplative spaces and names of victims etched in stone. While communicating loss and grief, both of these strategies usually evade any real political action or consideration of the complexities of gun violence or its causes. Mirroring the stalemate in our political dialogue around guns and their proliferation, our dominant strategies of memorialization similarly offer little more than "thoughts and prayers". In what ways can contemporary art break through these evasions and even prompt dialogue or change around the complex array of issues that arise with the increased presence of guns in American society? How can art generate experiences for viewers that allow for a more complex consideration of gun-related violence than the cycle of grief seen in immediate and permanent memorials? In this paper, I survey works of art that produce possibilities for transformative conversation around the issue by considering guns as what Bruno Latour calls "actants". I begin by examining guns in the gallery, first offering a new readings of Chris Burden's Shoot (1971) and Marina Abramović's Rhythm 0 (1974), both of which notoriously included real firearms, and then turning to sculptural projects that literally disarm guns, rendering them deliberately strange and prompting complex conversations about their material presence in American life. I then shift focus towards the public sphere to consider works by Krzysztof Wodiczko, Jenny Holzer, and Michael Rakowitz, artists who rewire established circuits of monumental commemoration, public space advertising, and vernacular immediate memorials to generate a sense of distance, and even a safe space for dialogue in the public realm.
\end{abstract}

${ }^{1}$ Miami University, Oxford, OH, USA. *email: dellarab@miamioh.edu 


\section{Introduction}

un violence impacts our experience of public spaces, including how we represent and memorialize mass shootings in public ways. Immediate memorials, complete with flowers and other ephemera, frequently appear at the sites of gun violence, at times to be followed by permanent memorials with contemplative spaces and names of victims etched in stone. Erika Doss (2006, p. 315) argues that the material abundance of immediate memorials at sites of collective trauma often remains "frozen in emotional catharsis" and disengaged from social and political action. Harriet Senie (2016) contends that permanent memorials like the one built at the site of the Columbine school shooting similarly engage in various denials. Designed often with the explicit input of grieving families, they evade any historical perspective or examination of critical issues in favor of producing what Senie calls "symbolic cemeteries". Mirroring the stalemate in our political dialogue around guns and their proliferation, our dominant strategies of memorialization similarly offer little more than "thoughts and prayers".

In what ways can contemporary art break through these evasions and even prompt dialogue or change around the complex array of issues that arise with the increased presence of guns in American society? How can art generate experiences for viewers that allow for a more complex consideration of gun-related violence than the cycle of grief seen in immediate and permanent memorials? In what follows, I outline moments where contemporary art intersects with the issue of gun violence in ways that prompt dialogue and connect the material presence and political issue of guns to other structures of violence. Looking specifically to art that hinges on the material presence of guns in society, either through including or representing them in the gallery or through the use of transitional objects to address the presence of guns in public spaces, I argue that these artworks model ways for transforming the larger cultural conversation around guns and gun violence.

To begin, I examine guns in the gallery. I offer a new reading of how two of the most controversial artworks in the history of performance art employed actual firearms, demonstrating how social space was transformed by the presence or use of a gun. I then turn to sculptural projects that literally disarm guns, rendering them deliberately strange and prompting complex conversations about their material presence in American life. In the second half I turn to works by Krzysztof Wodiczko, Jenny Holzer, and Michael Rakowitz that reach beyond the gallery and into the public sphere, reading how they rewire established circuits of monumental commemoration, public space advertising, and vernacular immediate memorials through transitional objects that generate space for dialogue in the public realm.

In many ways the artworks I discuss in this paper consider the role of guns as actants in society, borrowing a term from Bruno Latour. While a rigorous application of Latour's actor-network theory is beyond the purview of this discussion, by employing this term I seek to unpack how the literal explosiveness of the objects in question-guns-should inform any discussion about them. The presence of an actual gun can stifle cultural and political discussion, arguably the aim of many "come and take it" opencarry demonstrations. Artworks can effectively dramatize this transformation of social space in order to produce (rather than evade) conversations around complex issues, allowing us to move past the stalemate and comprehend how the material proliferation of guns intersects with broader social justice concerns.

These artworks consider what guns represent, but also use various artistic strategies to examine how guns act within our society. Most of my examples come from a contemporary United States context, where the status of guns as actants is most vociferously challenged by the gun manufacturing lobby's common refrain "guns don't kill people, people kill people". Latour called this argument "sociological", critiquing its inability to comprehend technical mediation and the role of non-human agents in complex assemblages (1999, p. 177). As lawyer and activist Dennis A. Henigan (2016, p. 14) argues, this slogan and many others propagated by the National Rifle Association and other gun rights advocates are not only fallacies but deliberate attempts to "end thoughtful, rational discussion and replace it with clever catchphrases in service to an immovable ideology".

The strategies employed by the artists in what follows push past the debate-silencing sloganeering of the gun lobby, the political evasions that Senie and Doss critique in our forms of public mourning, and politicians' common refrain "thoughts and prayers". Rather than reifying trauma and grief or taking up arms in a bifurcated political debate, the most interesting of these artworks prompt new dialogic spaces. These complex constellations of actors and actants challenge and circumvent the devastating immediacy of the object in question-the gun and its trigger.

\section{Guns in the gallery}

The physical presence of a gun in a museum or gallery, as curators of guns in historical and art collections note, can immediately make many viewers uncomfortable (Tucker et al., 2018, pp. 756-757). Ornate firearms with inlaid handles and elaborate metalwork, often produced as gifts or symbols of truces and alliances, figure prominently in the often-popular Arms and Armor sections of museums and are displayed as rarified objects of art. Although historical guns are collected widely by museums of art and design, firearms produced after 1900 (when such objects produced the most catastrophic global carnage) are largely absent, an omission that parallels design's inability to completely reckon with the sometimes violent fruits of its labor (Fisher, 2018). More recent guns are included in military or historical museums, but they are often isolated from any act of violence in their museological treatment (Tucker et al., 2018, p. 749). Although these historical displays do much to advance technological understanding and military history, what would it mean to include a firearm in a museological display that dealt explicitly with its relationship to gun violence, suffering, and death?

Below I analyze two moments when guns entered into artworks: as working firearms in 1970s performance art, and as sculptures in contemporary artworks explicitly grappling with the political issue of guns in the United States since the 1990s. By rereading two canonical works of performance art through their inclusion of working firearms, I map the issue of guns onto a longer history of artists' engagement with questions of safety, danger, and the body and demonstrate how and why guns need to be disarmed in order to effectively have a discussion about them.

\section{Triggering performances}

To include a working gun within a work of art rather than isolate it behind a vitrine for the study of its design possibly best articulates the gun as actant, though it obviously poses a real and present danger. The trigger mechanism, which can cause immediate and irreversible harm at a single touch, charges any situation with the specter of violence and even death at the slightest provocation, raised temper, misunderstanding, or simple mishandling. This even enters into our everyday language when we speak of "triggers" within the context of education, discussion, and debate (Gerspacher, 2019). As Bruno Latour (1999, p. 179) tells us, the gun is neither an autonomous force nor a neutral object, but rather an actant. "Which of them, then, the gun or the citizen, is the actor in this situation? Someone else (a citizen-gun, a 
gun-citizen)". Latour calls this process "translation"-when the citizen holds the gun, actor and actant fuse together and a third agent emerges. This "citizen-gun" is entirely different than the citizen alone or even the citizen fused with another actant. In sum, the mere presence of a gun alters the relations between people in spaces, something articulated profoundly by two iconic pieces of performance art from the 1970s. ${ }^{1}$

Performance art was a direct challenge to the commodifiable art object, the supposedly neutral gallery space, and the traditional roles of both performer and audience. In the practices Amelia Jones (1998) called "body art"-performances emerging in the late 1960s and 70s that explored the body as a site of inscription-the dismantling of detached observation in the gallery is a means towards enacting a radical intersubjectivity that understands the postmodern subject itself as splintered and fractured. The role of non-human actants, specifically firearms, in two of the most canonical performances of the 1970s was integral to enacting this destabilization of the subject as well as, I argue, a clear depiction of how the presence of a gun transforms social space.

Shoot (1971) by American artist Chris Burden and Rhythm 0 (1974) by Yugoslav artist Marina Abramović are two of the most oft-cited and notorious moments of 1970s performance art. In Burden's work, the artist's friend and University of CaliforniaIrvine classmate Bruce Dunlap shot the artist in the arm with a 0.22 caliber rifle from a distance of fifteen feet in front of a small audience at F Space Gallery in Santa Ana, California. Dunlap was drafted into the Army and trained as a marksman but never served in Vietnam. His identity remained anonymous (to protect himself from any criminal charges) until 2015 when he participated in an interview for The New York Times (Kutner, 2015). For Rhythm 0, Abramović stood passive for six hours in Studio Morra in Naples, Italy in front of a table with 72 objects, some of which were benign and some of which were menacing, including a gun and a bullet. Audience members were invited to use objects on the artist as they desired as she stood passively beside them. Both works were minimally documented (though Burden did record Shoot in a brief video), and they are mostly known today through iconic black and white photographs.

Both projects foregrounded notions of responsibility, be that of the audience or artist. As Frazer Ward (2001, p. 117) argues, Shoot's inclusion of a small audience and Dunlap "limned the public as an arena of responsibility, of dilemma and decision-as an ethical realm". Abramović explicitly claimed full responsibility in her stated directions for Rhythm 0 even though she was, of course, radically passive and vulnerable to the transgressions of her audience (Demaria, 2004, p. 296). The presence of a working firearm raised the stakes within this ethical realm, perhaps as high as possible within an art gallery.

Although both works' notoriety hinges on the risky decisions of the artist (their inviting danger read as bordering on the pathological), both Shoot and Rhythm 0 staged the body of the artist as merely an object: Burden said of his work "In this instant I was a sculpture" and Abramović claimed "I am the object" in her text and instructions at the gallery. This subject-object fluctuation reworks body art's positing of intersubjectivity and much of feminist theory's mission against objectification (Renzi, 2013), and is staged specifically through the inclusion of a working firearm. The gun's potential for immediate deadly force-in Latour's terms the translation that occurred when it fused with the participants-had the potential to transform the body of the artist into a permanent inanimate object and furthermore abruptly ended both artworks. Burden's wound was supposed to be just a graze, but the bullet pierced his bicep and demanded immediate hospital attention, necessitating departure from the gallery. ${ }^{2}$ Abramović's act of submission, which included allowing her clothes to be cut off and her skin pierced with a blade, was abruptly terminated when one audience member placed a bullet in the gun, placed the gun in the artist's hand, and pointed it towards her head. ${ }^{3}$

The dramatic ethical situations created in each performance transformed the contemplative space of the gallery through the presence of a working gun, an object whose triggering mechanism realizes a brutal and purely mechanical reaction to minimal pressure. The gun was not materially transformed; it was neither symbolic nor metaphorical. Its utilitarian purpose was not only preserved but enacted. By placing this enactment within the gallery space, however, the artists simultaneously prompted consideration of the gun's actions (rather than its design) in aesthetic terms and destabilized the gallery's position as site of aesthetic contemplation. Although these works operated within the contained environment of the gallery, they exceeded, even violated, expectations of such spaces. The art gallery's "white cube" is traditionally a site of visual, not physical experience-as spaces of detached perception and interpretation, not direct and dangerous action. Following minimalism's transformation of the white cube into phenomenological space a decade earlier, Burden and Abramovic raised the stakes of that space through the incorporation of the gun.

Importantly, their transgressions played out against the backdrop of state violence and other threats to safety, breaking down the boundaries between the gallery and the spaces beyond. Shoot deliberately engaged the mediated distant violence of the Vietnam war experienced by the American public daily on television (Paulsen, 2017, pp. 75-78). With attention to the geographical location of F Space, Faye Gleisser maps Dunlap's misfire into Burden's arm onto contemporaneous LAPD "misfires" that led to the death of Chicanos in the surrounding Santa Ana neighborhood. Her reading argues that Shoot in many ways (both intentional and unintentional) explored "the boundaries of control set in place by a society ordered around the protection of paradoxically lawless and innocent white masculinity" (2018, p. 326). Abramović's performance occurred while Italy's "Anni di piombo" (Years of Lead) raged in the northern cities of the country. Although the artist cites her upbringing in communist Yugoslavia in a family with women war heroes as distancing her early work from 1970s feminism (Kaplan, 1999, p. 15), her performance cannot be separated from the broader threat of misogyny and violence women experience daily in spaces both public and private.

Exploring different geographies of violence, these performances hinged on the gun as actant, on its ability to create a palpable hazard and force predicaments of responsibility in the public sphere. The inclusion of a working firearm made these works both significant and notorious in the canon of performance art. It also limited the possibility and level of interaction, discussion, or debate between performers and audience members or passersby. If anything, these works demonstrate the impossibility of free interaction and participation when guns are present. Arguably none of these artworks could be produced again in a twenty-first century United States context. They would read completely differently to a contemporary American audience steeped in media reports of mass shootings and gun fatalities. The faster speed of news and publicity in the age of social media would also sensationalize the works even more, and potentially pose even graver security threats.

Although they were produced outside of Second Amendment debates, reading these artworks through their inclusion of guns underscores the many ways in which firearms intersect with cultural, legal, and aesthetic notions of safety in public and private spheres. When the issue at hand is the proliferation of guns themselves, the mere presence of a firearm, with its sudden and 
causal functionality, arguably prevents any productive aesthetic or political contemplation, potentially triggering further entrenchment on either side of the ideological battle over guns.

\section{Disarming sculptures}

In recent decades, artists have begun to take a critical eye towards the political issues surrounding guns and gun violence within American culture. Unloaded, a 2015 traveling group exhibition curated by Susanne Slavick, is one of the main gatherings of this kind of work. In the catalog essay, Slavick bookends her discussion by citing both devastating statistics and the inability to find common ground in the current political climate-something the selection of artworks hopes to work towards achieving. She concludes, "...the surfeit of weapons in this country ultimately endangers us all. It is time to disarm and unload" $(2015$, p. 8). The curatorial voice of this exhibition signals a particular ideological stance in support of gun control, but the artworks allow for more nuanced consideration of gun culture and how it intersects with gender, race, capitalism, and militarism more broadly.

Although of course significant works in painting, installation art, video art, and photography have grappled with this issue in recent years, I limit my discussion below to sculpture, exploring again the physical presence of guns (or objects that used to be or resemble guns) in the gallery. I look to how artists transform guns from weapons into sculptural invitations to dialogue. These sculptures explore how guns are distributed, fetishized, or designed, superimposing the gun's implicit danger with the rarified aura of the art object.

One of the most common sculptural strategies is to quite literally re-present and disarm the surfeit of weapons Slavick critiques: to repurpose, hack, or appropriate real, decommissioned guns by transforming them into sculptural objects. The resultant sculptures retain the hard, metal forms of guns, indicating both their former status as deadly weapons and the ease with which artists can acquire them. Through the process of appropriation, however, these sculptures transform the guns' status as actants by removing their ability to fire bullets, making them safe to leave unattended in the gallery, removing their most dangerous potential for violence, and imbuing them with an entirely different set of meanings.

Mel Chin's Cross for the Unforgiven (2002), a work the artist recreated in 2012 and that featured prominently in Unloaded, contains eight cut and welded AK-47 rifles in the shape of a Maltese cross (Fig. 1). Were the guns operational, they would fire upon each other, alluding to self-destructive cycles of violence and religion. Mel Chin also disarmed a Glock $9 \mathrm{~mm}$ handgun for his sculpture HOME y SEW 9 (1994), using the body of the gun to house a gunshot trauma kit complete with electronic locator, lifesaving bandages, saline IV, and other medicines. The work vacillates between conceptual art and design as the sculpture could paradoxically both threaten life or save it. In reality the kit has the capacity to heal, but visually it could be mistaken for a real gun if carried outside the gallery, endangering its carrier, particularly were they to be a person of color, as artworks I discuss in the last section explore.

Guns in the Hands of Artists, an exhibition realized by gallerist Jonathan Ferrara and artist Brian Borello in New Orleans in 1996 and 2015, similarly disarmed real firearms through a community gun buyback program. Artists transformed the collected and decommissioned firearms into artworks whose sale further funded the buyback, merging the strategies of appropriation and social practice. The project has since spawned a related non-profit organization and traveled to other cities in the United States. This model echoes the 1995 initiative Transforming Arms into

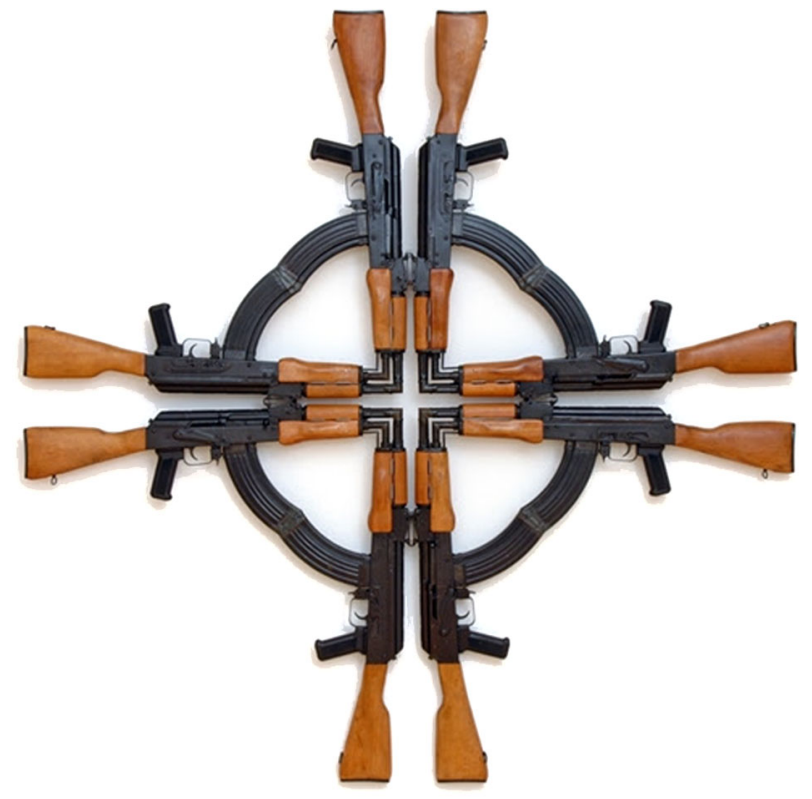

Fig. 1 Mel Chin, Cross for the Unforgiven (1/3), 2012. AK-47 assault rifles (cut and welded). $54 \times 54 \times 3$ in $(137.16 \times 137.16 \times 7.62 \mathrm{~cm})$. A Maltese cross of the Crusades, made from eight AK-47s, the international symbol of resistance to the West. This figure is not covered by the Creative Commons Attribution 4.0 International License. Reproduced with permission of $\mathrm{Mel}$ Chin. (c) Mel Chin. All rights reserved.

Ploughshares in the wake of the Mozambique Civil War (1976-1992) where artists made sculptures out of AK-47s used in the country's violent conflict (Tester, 2006) and Pedro Reyes's transformation of weapons collected and destroyed by the Mexican army into musical instruments.

Another disarming strategy creates guns out of overtly nonthreatening materials, trading in the hardness of metal for the pliability of textiles. In comparison to the masculine connotations of working, welding, or otherwise transforming hard metal, Slavick (Tucker et al., 2018) notes that artworks created through stereotypically feminine crafts explore the relationship between gun culture, gun violence, and gender. Natalie Baxter's Warm Gun series (2015-2018), for example, are soft replicas of assault weapons using colorful patterns and quilting techniques. Other artists connect craft with activism or contemplation: Stephanie Syjuco made her crochet pattern in Standard Issue Smith \& Wesson (2006) downloadable for anyone to make, and A.R. Drew's multimedia installation Bubblegum, Bullet Holes, and the Absurdity of It All (2017) features a knit sculpture of the word "Enough" by Brooke Marks-Swanson, featuring 79,080 stitchesthe number of gun incidents that occurred during the course of crafting her work.

Jen Edwards's crocheted replicas of historical firearms are explicitly designed to bridge the pro- and anti-gun divide and spark conversation in the gallery (Fig. 2). Their meticulous construction explores the history and craftsmanship of each weapon while also deliberately appearing "absurd enough to 'disarm' the viewer" (A Loaded Conversation, 2017). Altogether the sculptures make up A Loaded Conversation, an interactive exhibition aimed at sparking dialogue around guns through the physical handling of sculpture. Assisted by docents trained in conflict resolution, viewers are invited to handle the crochet sculptures with white gloves and discuss firearms in the gallery. A small plaque on the gun's history complements the period-inspired wood display rack of each piece, mimicking the displays of collectors and museums. Once handled, participants can interact with one of the gun's 


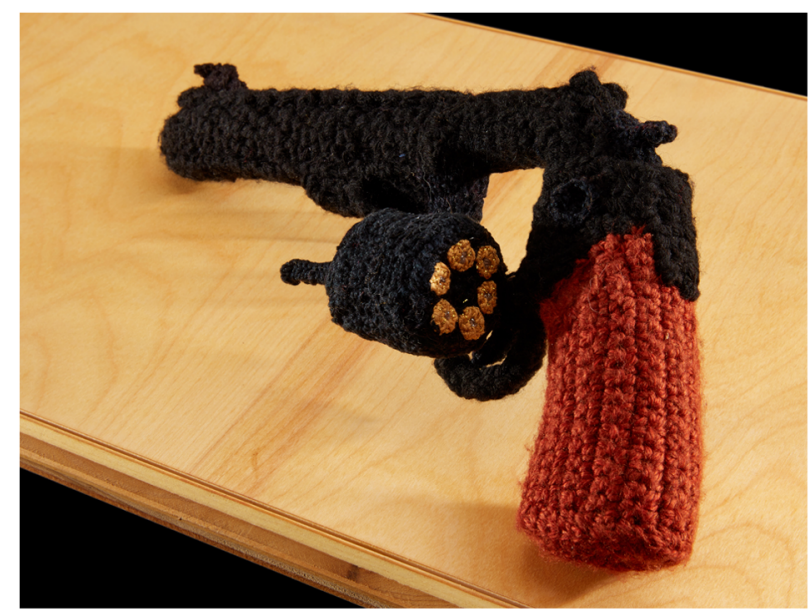

Fig. 2 Jen Edwards, Smith and Wesson Model 29 (detail), 2016. Crochet sculpture and part of the interactive exhibition A Loaded Conversation. Photo Rob Wolpert. This figure is not covered by the Creative Commons Attribution 4.0 International License. Reproduced with permission of Jen Edwards. (c) Jen Edwards. All rights reserved.

design elements, such as the removable magazine on the AR-15 filled with individually crocheted bullets or the screw-on silencer on the Walther PPK, the preferred weapon of James Bond. Participation in the show prompts discomfort in the institutional and social space of the gallery stemming from the objects' resemblance to real firearms, the standard gallery taboo against touching works of art, and (in the Cincinnati iterations of the project) a midwestern proscription against discussing politics with strangers. This discomfort is superseded, however, by the spirit of playfulness the interaction and non-threatening materials elicit, something that becomes more disturbing as people hold toscale replicas of AR-15s (weapons used often in mass shootings) or guns used by Nazis while smiling, laughing, and posing for Instagram. Edwards notes that most of the conversing patrons concurred that more restrictions on guns would be reasonable and effective, though "assumptions still took place on both sides" (2019, personal communication, 26 June). Although Edwards's stated interest in overcoming her own fear of firearms as a reason for producing the sculptures makes the exhibition's politics hard to pin down, the project succeeds in engaging viewers. Participants are prompted to understand the power and consequences of guns as objects in their hands, even if deliberately teetering dangerously close to enacting their material fetishization.

In all of these works and many others like them, contemporary artists push buttons, raise eyebrows, and even create bridges. Whether deliberately provocative and disturbing or contemplative and mournful, these works move past platitudes, empty rhetoric, and politically evasive memorialization. They do so, however, largely within the confines of the white cube gallery space and often in artworks set within established modes of observation and contemplation. These works run the risk of "preaching to the choir" as Robert Longo said of Death Star (2018), a massive spherical sculpture made of 40,000 AR-15 bullets in response to American gun deaths. ${ }^{4}$ Although "preaching to the choir" can effectively affirm, energize, and activate people already willing to attend art exhibitions, these practices have limited reach beyond the gallery. Artists seeking to bring dialogue about guns into the public sphere often have to negotiate different considerations of safety and audience response, requiring something other than the real or represented presence of guns. Instead, artists turn to strategies that speak to a broader audience and mobilize public feeling beyond the cycles of grief and "thoughts and prayers".

\section{Creating space for dialogue in the public sphere}

When examining art outside of the gallery, not only do wider potential audiences have to be taken into consideration, but also established forms of art in the public realm. Monuments and memorials, testaments to "always remember" or "never forget" triumphant or tragic collective memories, proclaim official histories in public contexts. Erika Doss (2010, p. 13) argues that memorials are "archives of public affect", reading the contemporary boom in memorial production-what she calls "memorial mania" - through the lens of public feeling. She writes, "Contrary to a Habermasian vision of a public sphere in which rational citizens exchange ideas and come together in shared and progressive actions, contemporary American public life is especially marked by emotional appeals and affective investments" (2010, p. 16), a phenomenon that most certainly applies to the issue of gun violence. Although Doss critiques many of the memorials that arise from these outbursts of public feeling, especially in the politically evasive and at times even intolerant forms they may take, she does locate ways in which even the seemingly stultifying practices of immediate memorials to grief can be transformative. "Grief's affective potential in America lies in its ability to mobilize social and political action" (2010, p. 115), something she sees as exemplified in the participatory AIDS Memorial Quilt.

How can artworks model a form of engagement within the public sphere that mobilizes rather than entrenches the public through affect and reaches beyond gallery audiences? That engages public feeling in ways that do not atomize viewers on an already emotional issue but instead model forms of critical thinking or community action around gun violence as a social concern? As Jill Bennett (2005, p. 11) argues in relationship to artworks dealing with trauma, the most effective practices for art do not merely recreate the trauma, using "affective triggers as blunt instruments to engender fear and nothing more", rather, art can be radically empathic, joining affect and cognition, even prompting critical inquiry. Trauma, she argues "is never unproblematically 'subjective'; neither 'inside' nor 'outside', it is always lived and negotiated at an intersection...visual art presents trauma as a political rather than a subjective phenomenon" (Bennett, 2005, p. 12).

Artists can address public audiences through the creation and transformation of urban monuments, spectacular advertising, and participatory immediate memorials. The projects discussed below present the trauma of gun violence as political and relational in ways that address this wide audience. They demonstrate how art can not only function as a reflection or representation of society, but also overlap with and become part of redefining the social. This blurring of the presumed separation between the spheres of art and reality within socially engaged art is a concept that in many ways draws on the legacy of performance art, but it further opens up the work of art to co-production with other agents, actants, and spaces.

\section{Monumental projection}

Public monuments materialize symbolic ideas of the dominant culture in public space, claiming to speak for a community, city, or nation. Since the 1980s the art of Krzysztof Wodiczko has questioned the function of monuments in public spaces by projecting images and voices of people largely un- or underrepresented in official spaces of commemoration, including the homeless, immigrants, refugees, veterans, and victims and survivors of violence. The artist transforms public sculptures and 
architectural facades that often become invisible through the familiarity of daily exposure. He simultaneously invites the public to see these material surfaces anew through illumination and undercuts their symbolic function through image and sound.

These projects are rooted not only in the use of projected images as critique, but also in a deep and sincere commitment to listening to the experiences of surrounding communities. Central to this collaboration is what Wodiczko refers to as the "transitional object", a term he borrows from DW Winnicott's research into the role objects such as blankets play in a child's developing awareness of the separation between the internal/subjective world and the external/objective world. In interpersonal interactions, especially with regard to trauma, such objects afford the speaker an intermediary space "to play and achieve a distance, perhaps even an ironic distance, from the painful and impossible experience" in order to be able to share and communicate it with others (Wodiczko, 2000).

Wodiczko's work has thus far intersected with the epidemic of gun violence in the United States three times-twice deliberately developed through his concepts, and once unintentionally. In 1998, the artist realized Bunker Hill Monument Projection in the Charlestown neighborhood of Boston (Fig. 3). The community had recently experienced a rash of gang violence nurtured by the predominantly Irish-descendant neighborhood's code of silence. Working with the Charlestown After Murder Program, an organization started by Sandy King who lost two sons to gun violence, Wodiczko produced video portraits of community members breaking the code of silence and sharing their stories of loss while holding candles-a common practice for vigils that emerge in the aftermath of community violence. These vertical videos anthropomorphized the Bunker Hill Monument, a tall obelisk erected in the 1840s to mark the site of the early Revolutionary War battle.

In 2004, the artist produced St. Louis Projection, again in collaboration with a local group, St. Louis's Victims Advocacy Center. Rather than broaching a neighborhood code of silence, Wodiczko breached prison bars with voices of the incarcerated and their victims: the work featured the painful testimonies of six residents who lost loved ones to violence and the remorseful stories of prisoners serving time in the Missouri State Correctional Facility for violent or gun-related crimes. The speakers' voices were accompanied by projections of their hands onto the façade of the St. Louis Public Library, effectively making the building speak. This Beaux-Arts style building from 1912 proved a fittingly monumental surface for the work, despite being the backup choice. The original choice was the city's Old Courthouse, site of the infamous 1849 Dred Scott case, which declined permission after learning of the project's content, claiming it was "not historical" enough (Allen, 2004).

Both the Bunker Hill and St. Louis projections superimposed the testimonies of under-represented people onto the edifices of official civic identity and memory in a way that anthropomorphized the monumental structures that speak to official memory in public space. Laura Saltzman (2006, p. 29) sees Wodiczko's work as an extension of the social ontology of video. Drawing on the Latin root of "video", videre or "to see", she reads the medium as a declaration of bearing witness to a past chain of events. This therapeutic bearing witness collides with official memory on the surface of the monument, producing the kind of collision theorized by filmmaker Sergei Eisenstein as montage, only this synthesis is sculptural. It occurs in space and at the site of projection rather than at the cut between frames or shots-on the object rather than within the moving image. The montage both illuminates the monument and renders it strange, and this strangeness produces the kind of transitional object and distance necessary to produce both brave testimony and radical, transformative, and empathetic listening.

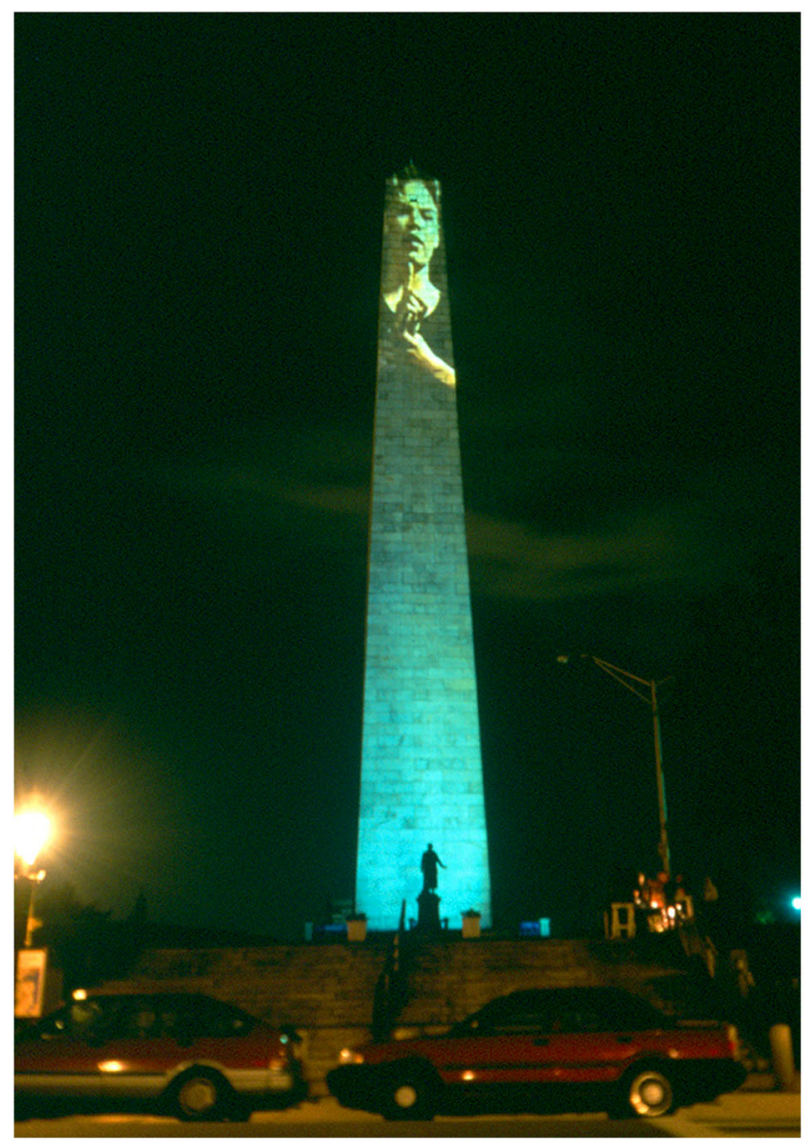

Fig. 3 Krzysztof Wodiczko, Bunker Hill Monument Projection, Boston, 1998. Public projection with video and sound. (c) Krzysztof Wodiczko Courtesy Galerie Lelong \& Co., New York. This figure is not covered by the Creative Commons Attribution 4.0 International License. Reproduced with permission of Galerie Lelong \& Co., New York. (c) Krzysztof Wodiczko. All rights reserved.

Although the stories projected in Charlestown and St. Louis did not exclusively involve guns, many of them did. One male prisoner in the St. Louis projection recalled, "why was I a seventeen-year-old boy carrying a gun? I guess looking back I could see myself and I could see all the insecurities, all the fears, all the anxieties that I had. When I looked at a gun I saw power" (Allen, 2004). The gun, in other words, transformed the subject, possibly leading him to commit acts he might not have otherwise. Wodiczko's practice is deeply rooted in a commitment to broad societal disarmament framed as an individual responsibility to realize the end of war (Deutsche, 2014, p. 10). To this end, he proposed transforming the Arc de Triomphe in Paris into the World Institute for the Abolition of War (2010) and in War Veteran Vehicle (2008) he replaced missile-launchers atop military Humvee vehicles with video and sound projectors to allow veterans to tell their stories in cities around the world.

The public nature of these projects meant that their messages reached a very different audience than artworks in the gallery. Although both projections only ran for a few nights (and indeed the artist maintains that the projections must be temporary), they reached passersby and members of the public not primed for an experience with contemporary art by leveraging the spectacle and scale of the projected image. Despite this evocation of spectacle, the project was still rooted in hearing and understanding the pain and trauma of the local community. The spectacle and the monument became the "transitional object" that enabled painful 


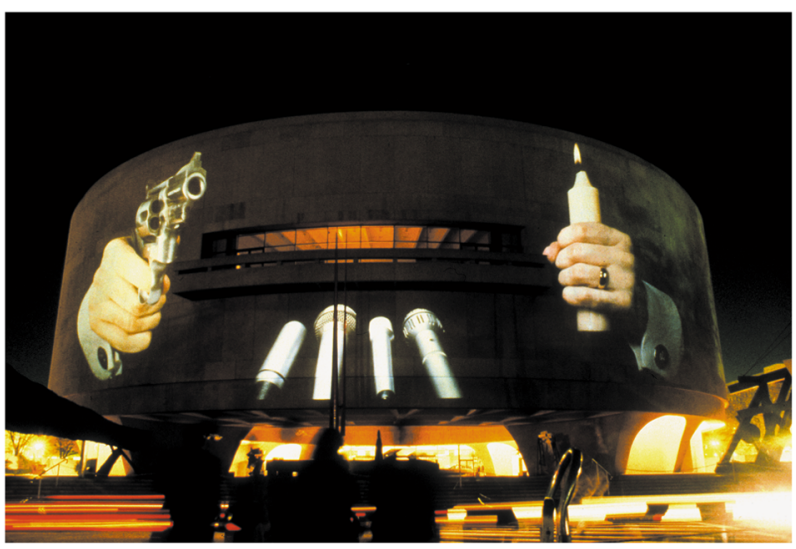

Fig. 4 Krzysztof Wodiczko, Hirshhorn Museum, Washington, DC, 1988/ 2018. Public projection with still image. (C) Krzysztof Wodiczko Courtesy Galerie Lelong \& Co., New York. This figure is not covered by the Creative Commons Attribution 4.0 International License. Reproduced with permission of Galerie Lelong \& Co., New York. (c) Krzysztof Wodiczko. All rights reserved.

communication to occur. In what ways could public art of this kind intervene not only in addressing local trauma from violence, but in the broader public debate around guns specifically?

The most recent intersection of Wodiczko's practice and gun violence in the United States proved just how thorny a direct approach to the topic of guns can be in public art. As part of the exhibition Brand New: Art and Commodity in the 1980s at the Hirshhorn Museum and Sculpture Garden in Washington, D.C., Wodiczko re-staged his 1988 slide projection on the cylindrical façade of the museum in February 2018 (Fig. 4). Made in the context of divisive rhetoric around the death penalty and reproductive rights during the 1988 presidential election, the work features one projected still image of a row of four microphones pointed at the museum's balcony flanked by two hands: one holding a candle, the other a pistol. With the 2018 projection scheduled for February 13-15, the project was halted after the first night in the wake of the Parkland school shooting on February 14.

In a statement released by the museum, the artist claimed "To me, the silence feels most respectful. In this case, not showing the projection shows respect and sensitivity to the people who suffer from this great tragedy" (Hirshhorn Museum, 2018). The image's resonance with the "thoughts and prayers" refrain of politicians and the building's proximity to the United States Capitol on the National Mall could have made it a powerful statement. Despite its very different context three decades prior, its thematic, visual, and site-specific relevance remained undeniable and could have further galvanized (or contributed to the momentum of) the almost immediate outpouring of activism from the students themselves (Capps, 2018). In this case, the explicit (though unintended) connection to gun violence as a political issue, as well as the visual presence of the image of a gun in a public space dense with symbolic structures and images on the same day as a mass-shooting made this project untenable as institutionally supported public art.

Many critics argued that this institutional silence was a mistake. Echoing Gary Wills's (2012) claim that the gun is our Moloch, Philip Kennicott (2018) maintained that the discomfort in the immediate aftermath of the mass-shooting at Parkland could have been transformative: "To see the gun projected on the Hirshhorn would be to say: This is our totem, this is our God, this is what we believe in. We might even rethink our identity as a massacre culture, in which these killings are meaningless and unaccountable bolts from the blue, and consider them, instead, as part of a perverted, uniquely American sacrifice culture, obligatory ritual carnage in service to the gun". To speak of totems and sacrifices is to think of a culture where objects hold an almost supernatural power. Conceiving of guns in this way forces us to reckon with the profound consequences of the material and symbolic presence of guns in American life, understanding them not as inert objects, but as actants.

The Hirshhorn, which is part of the federally funded Smithsonian Institution, was put in a difficult position given the political climate and their institutional implication in national politics. Furthermore, given Wodiczko's sincere commitment to working with traumatized communities and allowing their testimony to drive the work, I certainly understand why he would not want to appear to be piggypacking onto a raw and recent tragedy with pre-existing work and without communicating with victims. Although the museum did eventually make up the canceled projection nights in the following month, the opportunity to make an immediate, direct, and challenging statement about guns in public space was arguably lost, save for an unlicensed projection of Wodiczko's image onto a storefront in another neighborhood by D.C. artist Robin Bell. Given the difficulty with addressing controversial material within state-funded public venues, ${ }^{5}$ perhaps more overtly political statements about this particularly divisive issue are better made through spontaneous and unlicensed interventions such as those Wodiczko created earlier in his career.

\section{Mobilized frustration}

American artist Jenny Holzer is best known for her work with language, stretching back to her early Truisms series begun in the late 1970s. These ambiguous and often deliberately contradictory maxims entered into public space and challenged the rhetoric of both advertising and popular proverbs. They first appeared on paper flyers posted illicitly by the artist around Times Square. They were then were animated in 1982 as part of the Messages to the Public initiative on the Spectacolor electronic billboard in Times Square. This addition of temporality to her work signaled a major change in her practice that continues to inform much of her artwork in projection and LED sculpture in both the public sphere and the gallery. Like Wodiczko and other postmodern artists who rose to prominence in the 1980s, Holzer intervened in public space, using its dominant forms of communication as "both a target and a weapon" (Foster, 2003, p. 1038).

In 2018, Holzer wrote a new series of phrases and statements inspired by the activism of student survivors following the Parkland shooting and detailing her exasperation over gun violence in the United States. As Leah Pires (2018) suggests, "The slippery ambiguity of her early posters is here supplanted by the explicit condemnation of a system that enables gun violence". The phrases formed the basis for her public artwork IT IS GUNS (2018), as well as a related LED gallery installation made for the Tate Modern in London. In the public artwork, Holzer broadcast her phrases on a box truck equipped with LED screens on its two sides and rear (Fig. 5). Words communicating panic, such as "AMERICAN STUDENTS SHOT", "SCREAM AGAIN", "SHOT UP", "DUCK AND COVER", and "STAY WITH ME NOW" flashed across the truck's screens along with more retrospective phrases like "TOO LATE NOW", "IT IS GUNS", "GUN LOBBY", "THE PRESIDENT BACKS AWAY", and "GUN MONEY". These terms and phrases flashed in white letters against a black ground in the signature sans-serif font the artist uses in many of her public artworks. They demand attention and communicate instantly.

Like Wodiczko's projections in Charlestown and St. Louis, Holzer's animated truck had a deliberate strangeness to it that 


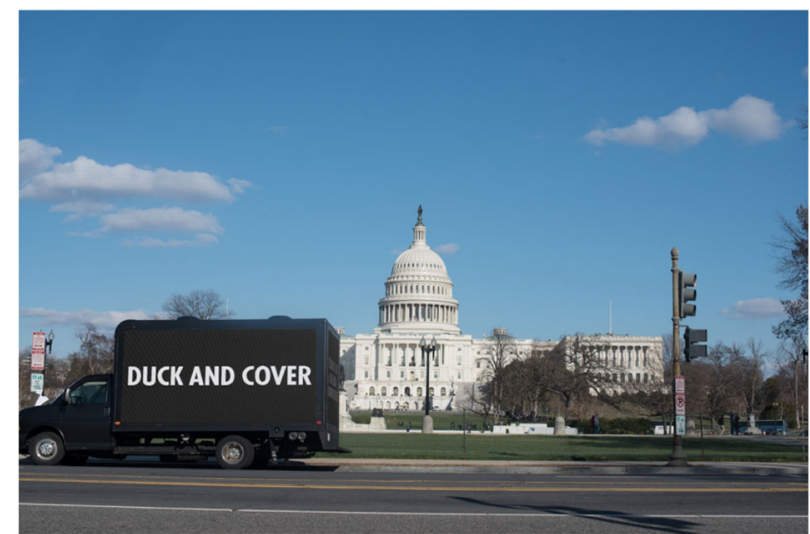

Fig. 5 Jenny Holzer, IT IS GUNS, 2018, March 9, 2018, Washington, D.C. Public artwork in multiple cities. Photograph by Catapult Image. This figure is not covered by the Creative Commons Attribution 4.0 International License. Reproduced with permission of Jenny Holzer. (c) Jenny Holzer. All rights reserved.

engaged an unsuspecting viewer with the juxtaposition of attention-grabbing moving images and challenging words with mundane urban surroundings. Unlike the re-staged Hirshhorn projection, however, its condemnation of the gun industry was intended and explicit. A set of trucks launched separately, unannounced in New York, Los Angeles, Washington, D.C., Chicago, Miami, Atlanta, Tallahassee, and Dallas. The trucks infiltrated public spaces and networks of urban movement, moving past rush hour traffic and stopping in front of public spaces and iconic public buildings. The LED-delivered text became even brighter and more conspicuous as nightfall descended. Although in many cities the project coincided with the March for Our Lives demonstrations, the truck was not part of any organized event. The project's random visibility in public space allowed for the kinds of unanticipated encounters that reach audiences who may never visit art galleries.

Unlike Sign on a Truck, a public project of Holzer's during the presidential election of 1984 that included interviews with residents on the streets of New York, IT IS GUNS had no interactive or discursive component. Similarly, unlike her more recent gunrelated piece VIGIL (2019), where poems and testimony from Americans impacted by gun violence were projected onto Rockefeller Center in New York City, the flashing truck did not engage in established codes of mourning. The fleeting glimpses of the truck's moving images did not allow for developed or sustained conversation, but instead provoked an immediate sense of discomfort (and possibly a memorable sense of unease) in those who witnessed it, perhaps safely recreating in small doses the affective experiences of fear and panic that mass shootings induce. Such disruptions in public spaces, the brevity and urgency of the flashing text, and the frank declarative statement of the work's title begin the conversation, though the work does not linger to facilitate it. The trucks constitute an effective and necessary provocation and call to action, but when we dig deeper into the issue, it becomes clearer that gun's impact on communities intersects with other forms of structural and political violence.

\section{Accumulation and intersection}

Although events like the Parkland mass-shooting generate some of the most passionate cries for reform, gun violence is not limited to civilian homicide, and gun deaths affect various communities differently. A full discussion of the threat guns pose to safety must include suicides (the vast majority of gun deaths), police shootings (which disproportionately impact communities of color), and how guns intersect with structural violence, toxic masculinity, poverty, systemic racism, and a militarized police force. The killing of Tamir Rice, a twelve-year old AfricanAmerican boy, outside of a recreation center in Cleveland, Ohio by a white police officer in 2014 galvanized Black Lives Matter activism. The boy had been playing with a toy gun with the orange safety tip removed. This modification became a fixation in the grand jury hearing and led to yet another set of dismissed charges for a white police officer who killed an unarmed black person. ${ }^{6}$

In A Color Removed, Chicago-based American artist Michael Rakowitz addressed the removal of the orange safety tip-a subtraction of color that destabilized the object's status as benign toy and that led to the killing of a person of color. It became a point of departure for this 2018 socially-engaged project at SPACES Gallery in the Ohio City neighborhood of Cleveland. The work stemmed from the artist's 2015 lecture at Case Western Reserve University in which he offered a somewhat quixotic proposal to remove the color orange entirely from the city in response to the police shooting. Doing so would be an effort to engender dialogue about the intersection of the right to safety, racism, and police-community relationships. SPACES Gallery and curator Christina Vassallo joined the project very soon after, and it took off with the support of the inaugural contemporary art triennial FRONT International in 2018. The project culminated in an iterative exhibition of orange objects collected from eleven bins placed around the city.

Like the second version of Guns in the Hands of Artists, which took place at the Prospect New Orleans triennial, Rakowitz's project was part of the "biennial boom" that has reshaped much of the contemporary art world at the turn of the millennium (The Editors of ARTnews, 2015). Connected to regional tourism and economic development, the increase of international biennials in mid-sized industrial cities could be critiqued for ignoring or marginalizing local artists in favor of big stars with international credentials like Rakowitz. It was through food, a medium Rakowitz uses frequently in his work, that his project avoided this fate. At a communal dinner the artist referred to as a "crucial moment", Rakowitz, the gallery, local artists, and community activists came together and worked through how the project could be both part of this major art world event and rooted in the concerns of the community. The next day Rakowitz left for a residency in Palestine where he saw a video at a refugee camp about a young boy killed within a year of Tamir Rice's death and happened upon a mural of Rice in the city streets. At this point, he said, "the entanglements became clear" (Rakowitz 2019, personal communication, 3 May). The artists he collaborated with in Palestine were also invited to contribute to A Color Removed, and artists based in Cleveland made works that were featured in both the mass of orange objects and a group show on view in conjunction with Rakowitz's work.

Upon his return, Rakowitz met with Samaria Rice, Tamir's mother, and made lunch for her using spices brought back from his travels. Through this conversation she agreed to be part of the project and for her son's name to be used. Her contribution to the installation was a touching set of mixed-media poster boards that used toys to not only convey how young her son was when he was murdered but to also examine the legal and illegal ubiquity of guns in the state of Ohio. A central panel reads "Ohio is an opencarry state" with "NRA" running down a row of orange toy guns and plastic toy police badges. These mass-produced, plastic toys haunt us with the violence imposed on a boy of color by their real-life counterparts (Fig. 6).

Throughout the rest of the room orange objects flooded the gallery, forming separate assemblages and surrounding a large table that doubled as a discursive space where the artist prepared 


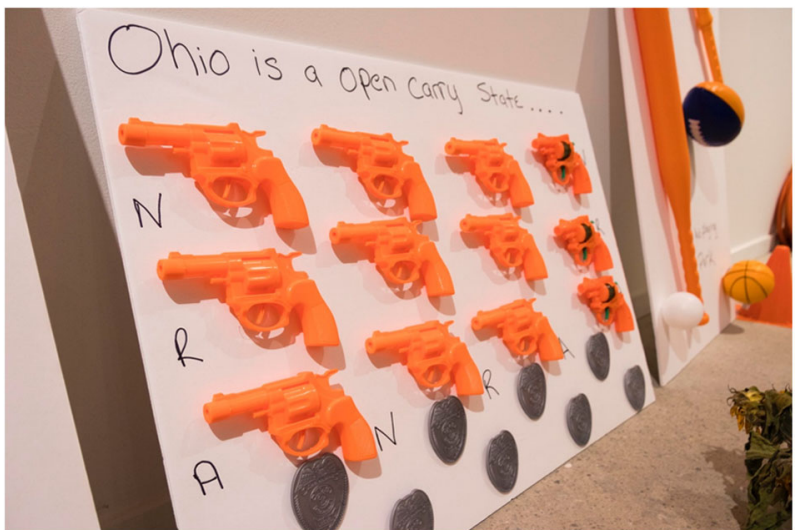

Fig. 6 Samaria Rice's panel at Michael Rakowitz, A Color Removed, 2018, organized by SPACES for FRONT International: Cleveland Triennial for Contemporary Art. Photograph by Jerry Mann. This figure is not covered by the Creative Commons Attribution 4.0 International License.

Reproduced with permission of SPACES. (C) Jerry Mann. All rights reserved.

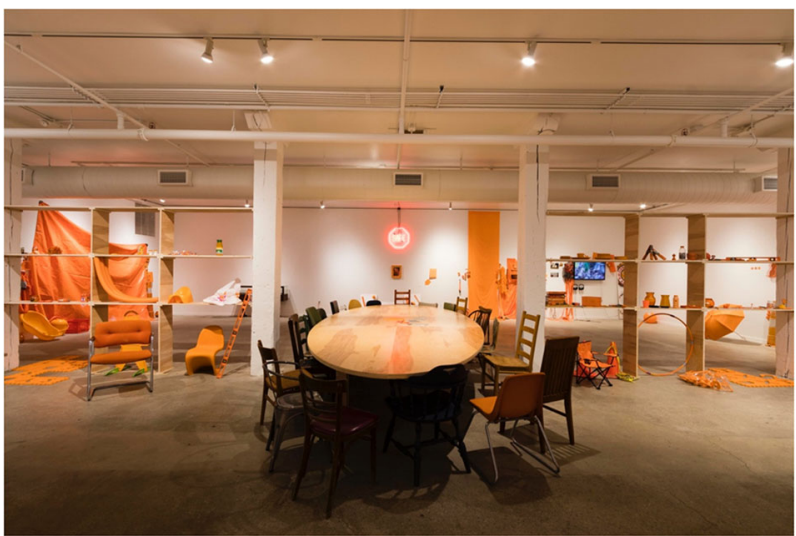

Fig. 7 Michael Rakowitz, A Color Removed, 2018, installation organized by SPACES for FRONT International: Cleveland Triennial for

Contemporary Art. Photograph by Jerry Mann. This figure is not covered by the Creative Commons Attribution 4.0 International License.

Reproduced with permission of SPACES. (c) Jerry Mann. All rights reserved.

meals (many of which featured dates, a word that fortuitously translates to "tamir" in Arabic) and the gallery held conversations and events (Fig. 7). The project statement calls the work "a provocation to generate many others", stating that the artwork "does not want a place at the table but would rather be the table and construct an environment where fearless listening can enable fearless speaking" (Rakowitz et al., 2018, p. 2). The artist's sincere commitment to listening to the voices of members of the communities he works with stems in part from studying with Wodiczko at M.I.T. and helping out with Bunker Hill Monument Projection in 1998. The objects were not autonomous aesthetic or conceptual statements in themselves. Instead they became an ever-changing assemblage that delineated and facilitated an intersubjective exchange of ideas and empathy.

Rakowitz's practice sits most squarely within what has come to be called socially-engaged art or social practice and involves what Grant Kester (2004) calls "dialogical aesthetics". Kester's concepts and the robust critical debate surrounding this field (Bourriaud, 1998; Bishop, 2004, 2012), largely concentrate on the boundaries of art, politics, and aesthetics in the philosophical and critical consideration of social interaction as art. What is perhaps left

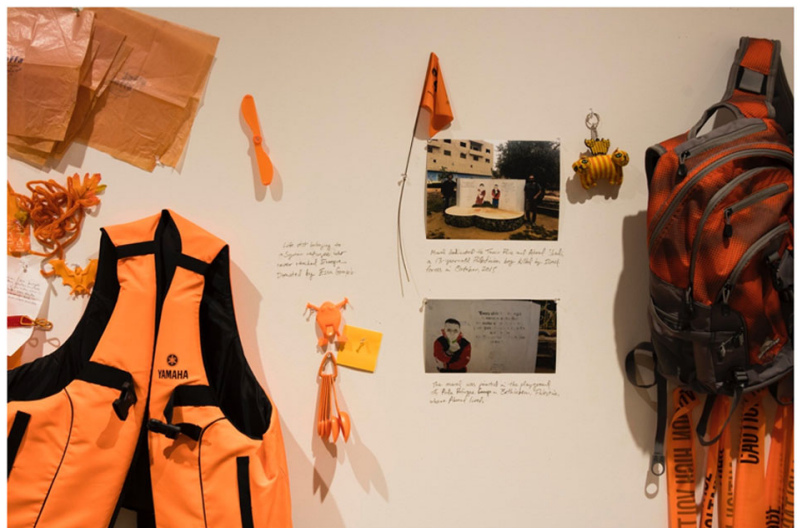

Fig. 8 Michael Rakowitz, A Color Removed, 2018, organized by SPACES for FRONT International: Cleveland Triennial for Contemporary Art. Photograph by Jerry Mann. This figure is not covered by the Creative Commons Attribution 4.0 International License. Reproduced with permission of SPACES. (c) Jerry Mann. All rights reserved.

under-evaluated, however, is the role of objects as facilitators within social exchanges.

Objects again perform transitional functions, in therapeutic, gustatory, and metaphoric ways. "If we need an indirect way of talking about black and white, maybe we can talk about red and yellow", Rakowitz said (Steinhauer, 2018). At SPACES, objects not only created space for participants to speak to the broader public, but also enabled a diverse set of members of the community to speak with each other, both directly and through their orange surrogates. The objects participated in the discursive life of the project as much as the participants did. For Rakowitz, it was important that he did not edit the things that came into the gallery (especially as an artist not from Cleveland). He allowed their accumulation to have life of their own, relinquishing control of the project and embracing doubt (personal communication).

The array and presentation of orange objects appropriated established vernacular tropes for community expressions of solidarity and grief. The adoption of a color, whether a black arm band or orange clothing for gun safety, ${ }^{7}$ has often signified a form of resistance in the face of tragedy. The project also assumed the accumulative logic and visual impact of the immediate memorial: the ever-growing assemblage of objects was arranged along vertical walls that viewers could survey and peruse, each thing traceable to a specific person's gesture of mourning or reflection and the entire collection expressing the affective outpouring of a community. Only with A Color Removed, the assemblage was not at all an immediate memorial. Taking place over three years after Tamir Rice's death, the project worked to both keep the boy's memory alive and point directly to how the injustices that caused it still persist. The plastic and mass-produced objects shared only the formal qualities of their garish, yet visually impactful, hue, merging a seemingly kitschy and idiosyncratic collection of found objects with the visual impact of color field abstraction.

A used tarp the size of a typical Abstract Expressionist painting hung askew on the wall next to a toy octopus, a t-shirt bearing the slogan "Stop Mass Incarceration", a traffic cone, a flattened orange soda bottle, and other detritus. Elsewhere Tide bottles, safety vests, Halloween candy buckets, extension cords, Cleveland Browns gear, and candy wrappers co-existed with more haunting objects, like a sign reading "Children at Play", toy guns, and a life jacket belonging to a Syrian refugee who never reached Europe (Fig. 8). Embracing the quixotic spirit of the project, one participant sent in a letter and photograph of FirstEnergy Stadium, home to the Cleveland Browns and 67,985 orange seats. When 
thrown together in the exhibition, the objects vacillated between evoking safety and threat, preciousness and throwaway excess, prompting a larger discussion about who and what is valued enough to feel safe and why.

Beyond the discursive and affective exploration of community grief and violations of safety achieved through the accumulation of orange objects, key installations within both Rakowitz's ongoing piece and the adjacent exhibition also explored the danger of seemingly benign objects in an increasingly armed society, particularly for people of color. A small display case towards the back of the main gallery included artifacts from the history of the production of toy guns, underscoring their connection to the capitalist gun industry in the wake of the Civil War, as well as their various intersections with police violence. Amber N. Ford's series of photographs, Mistaken Identity (2018), featured individual objects against a black background: keys, a wallet, a candy bar, a hairbrush, an iPhone, and toy guns-all objects that, when held by people of color, were allegedly mistaken for weapons by police, leading to more deadly "misfires". These objects communicate grief as well as outrage. Unlike the objects that amass at the immediate memorials Doss critiques, these accumulations and collections point directly towards political and systemic reasons for the tragic loss of life. In doing do they mobilize affect in ways that potentially breaks out of the endless feedback loop of grief, perhaps even moving towards a space of meaningful change.

Through both the participatory drop boxes and the community dinners and dialogues hosted at SPACES, the exhibition merged the gallery with the public realm, using the seemingly random objects to generate discussion not only around police shootings, but also on the right to safety itself. This oscillation between the realm of art and the public sphere mirrors how the project was both anchored in a local tragedy and able to "consider the endemics of gun violence, militarism, and racism across American cities as well as global ones" (Rakowitz et al., 2018, p. 2). As Christina Vassallo (2019, personal communication, 26 June) notes, the project demonstrated how such a work can appeal to and receive validation from both art world aficionados and community members, that art is not static and reclusive but can be relevant, necessary, and dynamic.

\section{Conclusion}

The immediate cause-and-effect mechanism of the trigger maps poorly onto the search for causes for the epidemic of gun violence in the United States. Too often news cycles and pundits ignore the complexity of gun violence as an issue, exaggerating the effects of mental illness or violent video games instead of thoughtfully researching the intermingling of social issues (like race, gender or class) with the material presence of guns themselves (Metzl and MacLeish, 2015). The political bifurcation of the issue, exacerbated by the slogans and rhetoric of the NRA, means that most debates simply lead to deeper entrenchment. This is particularly debilitating for interactions between strangers and in public spaces, exchanges that are arguably integral to a healthy democracy and cosmopolitanism (Sennett, 2017). Open-carry demonstrations and their attendant "come and take it" slogan invoke free speech in order to actually stifle necessary interaction and discourse. The presence of real guns instills fear and shuts people up.

What would it look like to use strategies like Edwards's interactive, crocheted guns and Rakowitz's dialogic accumulation of objects from the public to create opportunities for rich and meaningful discussions among those along the whole spectrum of the gun debate? Could the projects of artists in and beyond the gallery be the "table" that enables "fearless listening" and "fearless speaking"? Creating such dialogues might break the cycle of grief that defines so much of our memorial practices and contributes to the continual call for "thoughts and prayers". Uninhibited and productive conversations might help us understand the implications of the unfathomable material and symbolic proliferation of guns in American culture. This understanding is necessary as a realist or idealist for curtailing-and even potentially ending-the equally unfathomable harm guns inflict on our bodies and lives.

For centuries art has taken up the dual tasks of depicting aspirational, utopian worlds and responding to the material and social conditions of the one we inhabit. In grappling with the complex issue of gun violence in the United States, contemporary art can, in serving (and even merging) both of these historical functions, move us past the impasse of ideological entrenchment and perpetual grief. By producing artworks that both directly confront and obliquely allude to the very real harm these objects can inflict on various communities, as well as empathically pointing to the complexities of the epidemic of gun violence in the United States, artists model how to transform the political conversation around guns. In the words of Latour $(2005$, p. 41), "Objects become things", which is to say that "matters of fact give way to their complicated entanglements and become matters of concern". Unlike matters of fact, which can be manipulated and critiqued in the age of fake news and alternative truths, matters of concern are complex gatherings that allow for the intertwining of multiple voices and perspectives without devolving into pure relativism. In considering how particularly terrifying objects (guns) produce an insidious and increasingly daily terror (gun violence and mortalities that, in the U.S., far surpass rates in all other developed countries), the artworks discussed above invite us to take up this matter of concern in ways that could possibly transform the debate and move past the ideological standoff.

\section{Data availability}

Data sharing not applicable to this article as no datasets were generated or analyzed during the current study.

Received: 27 June 2019; Accepted: 7 January 2020; Published online: 28 January 2020

\section{Notes}

1 Firearms were enlisted in a number of other works of the twentieth-century avantgarde. Most notably French artist Niki de Sainte Phalle staged happenings for the completion of her Tirs (Shootings) (1961-63) paintings where bullets fired by the artist or participants pierced paint-filled balloons embedded in otherwise white-washed assemblages. It was through performance art, however, that the notion of the gun as an actant within a social space (rather than dramatic paintbrush or agent of destruction) was most clearly explored.

2 The unplanned trip to the hospital led to a fabricated story about how the artist got shot, as hospital staff are required to report all gun injuries and were convinced there was a domestic dispute of some kind. The artist claimed instead that he had gone hunting and that the rifle was on the table and a bottle of vinegar fell on it, a fabrication that "suspend[ed] the status of the act, in terms of public and private... reveal[ing] the instability of the legal definitions of those categories" (Ward, 2001, p. $124)$. The assumed credibility of the fabricated story was also arguably a product of the artist's privilege as a white man (Gleisser, 2018).

3 Accounts differ as to whether security, the artist, or other participants were the ones to intervene, but all agree that it was the insertion of the bullet into the gun and the pointing of the gun at the artist's head that ended the performance (Renzi, 2013, p. 124)

4 The number of bullets draws from CDC data on the total gun fatalities in 2017, which was 39,733. Longo made an earlier version of Death Star in 1993 in response to gun homicides using 18,000 0.38 caliber bullets. Press reports claim both numbers exclude suicides, but they do not-there were fewer gun homicides in 2017 than in 1993, though there were more total gun deaths, largely due to the rise in suicide.

5 Infamous controversies surrounding the cancelation or censoring of exhibitions of Robert Mapplethorpe and David Wojnarowicz in Washington, D.C. demonstrate this 
difficulty and span Jesse Helms's late 1980s Culture Wars to the rise of the Tea Party in 2010. Both of these events lead to guerrilla projections onto museum facades.

6 In addition to the toy's resemblance to a real handgun, police maintained that it was also difficult to tell the boy's age, suggesting that their defense for the shooting (which happened within seconds of the car stopping near Tamir Rice and without the dispatcher passing along the original 911 caller's claim that the gun was "probably fake") was that the boy appeared to be an adult carrying a real gun. Even if a genuine misunderstanding, considering that Ohio is an open-carry state, this defense still reminds us of the disproportionate number of black men shot by police while unarmed or legally holding a firearm. John Crawford III, while shopping for an air rifle at a Walmart, and Philando Castile, who merely told an officer that he had a licensed concealed weapon in his vehicle, were both shot and killed by police, to name just a few similar tragedies.

7 The non-profit Everytown for Gun Safety has adopted wearing the color orange as a strategy for people to signal their support for increased gun safety legislation.

\section{References}

A loaded conversation (2017) Jen Edwards. http://jenedwardsart.weebly.com/aloaded-conversation.html (Accessed 17 June 2019)

Allen G (2004) In St. Louis, healing the scars of violence with art. All things considered. National Public Radio

Bennett J (2005) Empathic vision: affect, trauma, and contemporary art. Stanford University Press, Stanford

Bishop C (2012) Artificial hells: participatory art and the politics of spectatorship. Verso Books, London

Bishop C (2004) Antagonism and relational aesthetics. October 110:51-79

Bourriaud N (1998) Relational aesthetics. Les Presse Du Reel, Franc, Dijon

Capps K (2018) After the Parkland shooting, the Hirshhorn removes an artwork on gun violence. Washington City Paper

Demaria C (2004) The performative body of Marina Abramović: rerelating (in) time and space. Eur J Women's Stud 11:295-307. https://doi.org/10.1177/ 1350506804044464

Deutsche R (2014) Un-war: an aesthetic sketch. October 147:3-19

Doss E (2010) Memorial mania: public feeling in America. University of Chicago Press, Chicago

Doss E (2006) Spontaneous memorials and contemporary modes of mourning in America. Material Religion 2:294-318

Fisher MM (2018) 'The most fascinating and well-designed artifacts of our time': collecting and exhibiting contemporary guns in the art museum. J Vis Cult 17:272-285. https://doi.org/10.1177/1470412918800006

Foster H (2003) Subversive signs. In: Art in theory 1900-2000: an anthology of ideas. Blackwell Publishing, Malden, pp. 1037-1038

Gerspacher A (2019) Feeds and triggers: On Martin Roth's In November 2017 collected a plant from the garden of a mass shooter (2017), In: Beyond "thoughts and prayers": gun violence, activism, and controversy in contemporary art. Presented at the College Art Association annual conference, New York, NY

Gleisser F (2018) Asco, Chris Burden, and the politics of the misfire. J Vis Cult 17:312-331. https://doi.org/10.1177/1470412918800480

Henigan DA (2016) “Guns don't kill people, people kill people”: and other myths about guns and gun control. Beacon Press, Boston

Hirshhorn Museum (2018) Statement regarding postponement of Krzysztof Wodiczko's projection on exterior of Hirshhorn. Hirshhorn Museum and Sculpture Garden | Smithsonian. https://hirshhorn.si.edu/news/press-release/ statement-regarding-postponement-krzysztof-wodiczkos-projection-exteriorhirshhorn/ (Accessed 25 June 2019)

Jones A (1998) Body art/performing the subject. University of Minnesota Press

Kaplan JA (1999) Deeper and deeper: interview with Marina Abramović. Art J 58:6-19. https://doi.org/10.1080/00043249.1999.10791935

Kennicott P (2018) Perspective | This would be the perfect time for the art world to address gun violence. The Washington Post

Kester GH (2004) Conversation pieces: community and communication in modern art, revised edition. University of California Press, Berkeley

Kutner E (2015) Opinion | Shot in the name of art. The New York Times

Latour B (2005) From realpolitik to dingpolitik: or how to make things public. In: Latour B, Weibel P (eds.) Making things public: atmospheres of democracy. The MIT Press, Cambridge, pp. 14-41

Latour B (1999) Pandora's hope: essays on the reality of science studies. Harvard University Press, Cambridge

Metzl JM, MacLeish KT (2015) Mental illness, mass shootings, and the politics of American firearms. Am J Public Health 105:240-249
Paulsen K (2017) Here/there: telepresence, touch, and art at the interface. The MIT Press, Cambridge

Pires L (2018) Issues \& commentary: truisms and lies. Art in America. https://www. artinamericamagazine.com/news-features/magazines/issues-commentarytruisms-lies/ (Accessed 25 June 2019)

Rakowitz M, Ford AN, King A, Lane MC, Washington R (2018) A color removed gallery pamphlet. SPACES Gallery

Renzi K (2013) Safety in objects: discourses of violence and value-the Rokeby Venus and Rhythm 0. SubStance 42:120-145. https://doi.org/10.1353/sub.2013.0007

Saltzman L (2006) Making memory matter: strategies of remembrance in contemporary art. University of Chicago Press, Chicago

Senie HF (2016) Memorials to shattered myths: Vietnam to 9/11. Oxford University Press, New York, NY

Sennett R (2017) The fall of public man, 40th anniversary edition. W. W. Norton \& Company, New York, NY

Slavick S (2015) Unloaded. SPACE Gallery, Pittsburgh, PA

Steinhauer J (2018) An artist honors Tamir Rice, one orange object at a time. The New York Times

Tester FJ (2006) Art and disarmament: turning arms into ploughshares in Mozambique. Dev Pract 16:169-178

The Editors of ARTnews, 2015. The Biennial Boom. ARTnews. http://www. artnews.com/2015/03/21/the-biennial-boom/ (Accessed 10 June 2019)

Tucker J, Adamson G, Ferguson JS, Garrett-Davis J, Goldstein E, Hlebinsky A, Miller DD, Slavick S (2018) Display of arms: a roundtable discussion about the public exhibition of firearms and their history. Technol Cult 59:719-769. https://doi.org/10.1353/tech.2018.0064

Ward F (2001) Gray zone: watching “shoot". October 95:115-130

Wills G (2012) Our moloch. The New York review of books. https://www.nybooks. com/daily/2012/12/15/our-moloch/ (Accessed 13 Sept 2019)

Wodiczko K (2000) Open transmission. In: Read A (ed.) Architecturally speaking: practices of art, architecture, and the everyday. Routledge, New York, NY, pp. $87-109$

\section{Acknowledgements}

The inspiration for this paper started with a panel I chaired at the 2019 College Art Association titled "Beyond "Thoughts and Prayers": Gun Violence, Activism, and Controversy in Contemporary Art" with presentations by Michelle Millar Fisher, Susanne Slavick, Arnaud Gerspacher, Nicole Scalissi, Eileen Boxer, and Joshua Smith, some of which are cited in this paper. I thank them all for such wonderful and inspiring work on this topic.

\section{Competing interests}

The author declares no competing interests.

\section{Additional information}

Correspondence and requests for materials should be addressed to A.D.

Reprints and permission information is available at http://www.nature.com/reprints

Publisher's note Springer Nature remains neutral with regard to jurisdictional claims in published maps and institutional affiliations.

cc) (i) Open Access This article is licensed under a Creative Common Attribution 4.0 International License, which permits use, sharing, adaptation, distribution and reproduction in any medium or format, as long as you give appropriate credit to the original author(s) and the source, provide a link to the Creative Commons license, and indicate if changes were made. The images or other third party material in this article are included in the article's Creative Commons license, unless indicated otherwise in a credit line to the material. If material is not included in the article's Creative Commons license and your intended use is not permitted by statutory regulation or exceeds the permitted use, you will need to obtain permission directly from the copyright holder. To view a copy of this license, visit http://creativecommons.org/ licenses/by/4.0/.

(C) The Author(s) 2020 